\title{
A produção brasileira de biodiesel: o caso da Brasil Ecodiesel
}

\author{
Junior Ruiz Garcia* \\ Armando Dalla Costa**
}

RESUMO - Este artigo tem por objetivo investigar a trajetória da empresa Brasil Ecodiesel destacando o processo de inovação empreendido e a organização de sua base agrícola, enfatizando seu papel de inserir a agricultura familiar ao agronegócio brasileiro. A Brasil Ecodiesel detém aproximadamente $22 \%$ da capacidade instalada de produção brasileira autorizada pela ANP e, na classificação que inclui somente as detentoras do Selo Combustível Social por volta de $26,5 \%$. Todas as suas unidades processadoras possuem o Selo Combustível Social. Essa firma representa um importante papel para o Programa Nacional de Produção e Uso do Biodiesel (PNPB) brasileiro, principalmente no que se refere à inserção da agricultura familiar à cadeia do biodiesel e à consolidação do processo de produção. Por fim, a empresa utiliza tecnologia nacional, fornecida pela Tecbio (Tecnologias Bioenergéticas), diversifica sua base de matéria-prima tanto no que diz respeito ao sistema de produção e variedades de matérias-primas quanto ao processo industrial (rotas tecnológicas).

Palavras-chave: Brasil Ecodiesel. Biodiesel. Agricultura Familiar.

\section{INTRODUÇÃO}

A retomada na elevação no preço do barril de petróleo e a manutenção dessa tendência, paralelamente à intensificação das discussões sobre os impactos ambientais decorrentes da queima de combustíveis fósseis impulsionaram a produção e o uso de biocombustíveis (etanol e biodiesel) no cenário internacional na década de 1990. Em poucos anos a produção mundial de etanol alcançou a marca de 50 bilhões de litros, dos quais 18,5 são produzidos pelo Brasil e por volta de 20 bilhões pelos EUA. No caso do biodiesel, estima-se que a produção mundial foi da ordem de 8,5 bilhões de litros em 2006, sendo que os principais produtores foram a Alemanha (3 bilhões de litros) e os EUA (1,1 bilhão de litros) (NERY, 2008).

Dentro desse cenário o mercado de biocombustíveis se mostra promissor seja em âmbito interno quanto externo, o que pode ser verificado pela rápida expansão desse setor no Brasil e, em outros países, tais como EUA, Alemanha, França, Itália, Indonésia e Índia. No Brasil,

* Doutorando em Desenvolvimento Espaço e Meio Ambiente, Universidade Estadual de Campinas. Endereço eletrônico: jrgarcia@ufpr.br .

** Pós-Doutor em Economia pela Université Jules Vernes, Amiens. Professor Adjunto do Departamento de Economia da Universidade Federal do Paraná. Coordenador do Núcleo de Pesquisa em Economia Empresarial (www.empresas.ufpr.br). Endereço eletrônico: ajdcosta@ufpr.br . 
a participação da cana-de-açúcar na renda agropecuária passou de 14\% para 21\% entre 2005 e 2007 (ABRAMOVAY \& MAGALHÃES, 2007), ademais conta com 370 unidades processadoras de etanol, que produziram mais de 21 bilhões de litros de etanol na safra 2006/07 (MAPA, 2008a \& 2008b), e com mais de 50 unidades de biodiesel com autorização da Agência Nacional do Petróleo, Gás Natural e Biocombustíveis (ANP), cuja capacidade instalada é de 2,85 bilhões de litros anuais (ANP, 2008).

A resposta do governo brasileiro foi a instituição do Programa Nacional de Produção e Uso de Biodiesel (PNPB) em dezembro de 2004, que conta com um conjunto de incentivos, cujo objetivo principal é estimular a integração da agricultura familiar ao agronegócio do biodiesel, diferente do que ocorreu no Pró-álcool (GARCIA, 2007). Este programa procura garantir a demanda de biodiesel no mercado através da obrigatoriedade da mistura de $2 \%$ ao óleo diesel, iniciada em janeiro de 2006, restrito ao volume de produção e, obrigatória a partir de janeiro de 2008.

A Brasil Ecodiesel foi constituída em 2003, empresa do setor de óleos vegetais que se insere no processamento de biodiesel. Em pouco mais de cinco anos tornou-se líder no mercado nacional em processamento de biodiesel (capacidade instalada e produção). Em 2007, todas as unidades processadoras da Brasil Ecodiesel alcançaram uma produção de pouco mais de 211,9 milhões de litros, o que representou 53,1\% do total (ANP, 2008).

Este artigo tem por objetivo analisar a expansão apresentada por essa empresa no setor de biocombustíveis. O referencial teórico empregado é o do crescimento da firma, sobretudo na literatura que iniciou com Penrose e nos autores da teoria evolucionária das empresas, com destaque para Nelson, Winter, Dosi, Freeman, entre outros. Entretanto, por motivos de espaço, neste artigo não tratamos da teoria e entramos, na sessão seguinte, nos aspectos relacionados à origem e o funcionamento do Programa Nacional de Produção e Uso de Biodiesel. A partir daí o artigo resgata o início e o desenvolvimento da Brasil Ecodiesel, desde 2003, ano de sua fundação, até princípios de 2008. Por fim, são apresentadas as principais conclusões.

\section{O PROGRAMA NACIONAL DE PRODUÇÃO E USO DE BIODIESEL}

O Programa Nacional de Produção e Uso de Biodiesel (PNPB) é uma resposta brasileira ao que está sendo realizado em âmbito mundial desde meados da década de 1990 no campo da pesquisa e da produção de energias alternativas ao petróleo. A década de 1990 marcou o início da 
produção comercial por alguns países europeus (Alemanha, França, Itália entre outros) e EUA de um sucedâneo ao óleo diesel produzido a partir de óleos vegetais, de gorduras animais ou residuais, o biodiese $\mathrm{l}^{35}$.

Em dezembro de 2004, o governo brasileiro lançou o PNPB, cujas principais diretrizes são: i) introdução sustentável do biodiesel na matriz energética; ii) promover a geração de emprego e renda para os agricultores familiares (principal objetivo); iii) promover a redução das disparidades regionais (ações diferenciadas no âmbito regional); iv) contribuir para uma redução nas emissões de poluentes; v) redução do volume de importação de óleo diesel; vi) disponibilizar subsídios fiscais e creditícios; e vii) propiciar uma regulamentação flexível (matéria-prima e o processo ou rota tecnológica).

Esse programa busca se diferenciar das tentativas das décadas de 1970/80, por meio de seu forte enfoque social, qual seja, a integração da agricultura familiar ao Agronegócio do Biodiesel. Para isso o governo disponibilizou um conjunto de instrumentos de política, como a criação de um mercado compulsório, isenção fiscal parcial ou total dos tributos federais; promoveu a padronização do ICMS; subsídios creditícios; criação do Selo Combustível Social.

A criação do mercado compulsório para o biodiesel está disposta na Lei no 11.097, de 13 de janeiro de 2005, que estabelece a obrigatoriedade da mistura inicial de 5\% de biodiesel ao óleo diesel. Essa mistura deve ser alcançada no prazo de 8 anos, sendo de 3 anos o período para se utilizar um percentual em caráter obrigatório e intermediário de 2\%. Assim, foi definido que a partir de $1^{\circ}$ de janeiro de 2008 todo o óleo diesel comercializado no país deverá conter, em caráter obrigatório, um percentual de 2\% de biodiesel. Esse percentual inicial perdurará até 2013, data em que essa proporção deverá ser elevada para 5\%.

No âmbito fiscal, o Governo propôs a seguinte tabela de isenção: 31\% de redução para mamona e palma, nas regiões Norte, Nordeste ou Semi-árido; 68\% de redução para agricultura familiar em qualquer região do país e com qualquer oleaginosa; e 100\% de redução para mamona ou palma, produzida pela agricultura familiar nas regiões Norte, Nordeste ou Semi-árido. No que diz respeito à tributação estadual ficou estabelecida uma Alíquota Padrão para o Imposto de Circulação de Mercadorias e Serviços (ICMS) (Convênio ICMS N 113, de 06 de outubro de 2006), a qual definiu uma alíquota de $12 \%$ para todos os Estados da Federação.

35 O biodiesel é um éster, metílico ou etílico, obtido a partir de uma reação química, a mais utilizada é a transesterificação, entre um óleo vegetal ou gordura animal ou mesmo óleos residuais e um álcool, etanol ou metanol, na presença de um catalisador. 
Em termos dos subsídios financeiros, o Ministério de Desenvolvimento Agrário (MDA) criou alguns instrumentos para o financiamento da produção de plantas oleaginosas para a agricultura familiar, os quais foram incorporados às linhas de crédito do Pronaf (CARVALHO, 2006): i) Pronaf biodiesel; ii) Pronaf Agroindústria; iii) Pronaf infra-estrutura; e iv) Pronaf diversificação, capacitação, Assistência Técnica e Extensão Rural - Ater, Inovação e Insumos.

O BNDES também lançou o Programa de Apoio Financeiro a Investimentos em Biodiesel que consiste: na participação do banco em até 90\%, em projetos que detenham o SCS, e até $80 \%$ para os demais projetos; o FINAME para a aquisição de máquinas e equipamentos que possam utilizar pelo menos $20 \%$ de mistura de biodiesel (B20) ao óleo diesel, com prazo de amortização 25\% maior e; redução das garantias reais de $130 \%$ para 100\% do valor financiado, com taxas de juros diferenciadas segundo o tamanho do empreendimento (MME, 2004).

Em meio a isso, o Governo Federal também instituiu o "Selo Combustível Social", componente de identificação que será concedido pelo MDA aos produtores industriais de biodiesel que estejam promovendo a inclusão dos agricultores familiares. A concessão do selo estará condicionada aos seguintes requisitos: aquisição de percentuais mínimos da matéria-prima utilizada no processamento do biodiesel da agricultura familiar, a qual esteja enquadrada no Pronaf; manter registro com documento comprobatório das aquisições totais de matéria-prima anual por um período mínimo de cinco anos e; assegurar assistência e capacitação técnicas a todos os agricultores familiares fornecedores de sua matéria-prima. Ainda o produtor industrial deverá firmar contratos com a agricultura familiar, ou seja, com todos os agricultores familiares e com seus representantes, pelo menos um deles (BRASIL, 2005a; 2005b).

Em contrapartida, o produtor ou empreendedor industrial que obtiver esse selo receberá incentivos fiscais, acesso a linhas de financiamento diferenciadas e facilidades para a comercialização. Ou seja, o produtor industrial de biodiesel detentor do selo obterá redução diferenciada no PIS/PASEP e COFINS, acesso a melhores condições de financiamento junto ao BNDES. Este selo poderá ainda ser utilizado para fins de promoção comercial (MDA, 2006).

Sobre a comercialização, o Ministério de Minas e Energia (MME) estabeleceu via Portaria n 4 $^{\text {483, de }} 03$ de outubro de 2005 as diretrizes para a realização de leilões públicos para aquisição de biodiesel. A realização desses leilões foi enquadrada na forma de licitação pública, inclusos na modalidade de pregão eletrônico por item, que serão organizados e realizados pela 
ANP. Esses leilões deverão estar em conformidade com o Regulamento para Aquisição de Bens e Contratação de Serviços da ANP.

Os fornecedores industriais de biodiesel interessados em participar desses leilões deverão: a) ser detentor do SCS ou apresentar projeto reconhecido pelo MDA como possuidor dos requisitos necessários à obtenção do selo e; b) apresentar os seguintes documentos: i) autorização da ANP para exercer a atividade no país e; ii) Registro Especial junto à Receita Federal do Brasil. Contudo, no sétimo leilão, realizado dia 14 de novembro de 2007, foi permitida a participação de produtores de biodiesel que não eram detentores do SCS (tabela 01).

TABELA 01 - CAPACIDADE AUTORIZADA PELA ANP DAS PLANTAS INDUSTRIAIS DE BIODIESEL: ABRIL DE 2008

\begin{tabular}{|c|c|c|c|}
\hline REGIÃO & $\begin{array}{l}\text { NÚMERO DE } \\
\text { EMPRESAS POR } \\
\text { REGIÃO }\end{array}$ & $\begin{array}{l}\text { CAPACIDADE ANUAL } \\
\text { ESTIMADA (M }{ }^{3} / \text { ANO) }\end{array}$ & $\begin{array}{l}\text { VOLUME TOTAL POR } \\
\text { REGIÃO VENDIDO EM } \\
\text { TODOS LEILÕES }\left(M^{3}\right)^{2}\end{array}$ \\
\hline Centro-Oeste & 21 & 971.900 & 392.749 \\
\hline Nordeste & 6 & 506.220 & 490.520 \\
\hline Norte & 5 & 158.700 & 135.560 \\
\hline Sudeste & 12 & 625.590 & 254.501 \\
\hline Sul & 7 & 589.200 & 320.910 \\
\hline TOTAL & 51 & 2.851 .610 & 1.594.240 \\
\hline
\end{tabular}

FONTE: Elaborado pelos autores com base em ANP (2008).

NOTAS: 1) 300 dias de operação. 2) representa o volume negociado nos 9 leilões da ANP.

Como pode ser observado nos volumes negociados nos leilões, o lançamento do PNPB conseguiu promover grandes repercussões no setor industrial. Outra variável que corrobora a adesão do setor industrial privado é a capacidade instalada de produção autorizada pela ANP. Segundo dados da ANP (2008), essa capacidade alcançou em janeiro de 2008, o volume de 2,85 bilhões de litros anuais, capacidade distribuída em 51 plantas industriais (tabela 01).

\section{BRASIL ECODIESEL E A PRODUÇÃO DE BIODIESEL}

A empresa Brasil Ecodiesel Indústria e Comércio de Biocombustíveis e Óleos Vegetais S.A. é uma companhia de sociedade anônima de capital aberto desde 2006, fundada em 2003, com sede no Rio de Janeiro. É uma empresa dedicada só à produção e comercialização de biodiesel. Seus principais objetivos são: i) buscar a liderança de mercado; ii) se destacar no mercado internacional; iii) estruturar as cadeias produtivas para a produção de matérias-primas; iv) manter uma forte relação com o agronegócio e a agricultura familiar; v) buscar a dispersão geográfica com o objetivo de diversificar sua rede de fornecimento de matéria-prima, bem como otimizar o processo logístico; vi) controlar o processo industrial de forma flexível e a promoção 
constante da inovação nas técnicas agrícolas na busca por novas fontes de matérias-primas e; vii) contribuir de forma efetiva para o desenvolvimento econômico sustentável local (BRASIL ECODIESEL, 2008a).

QUADRO 01 - CRONOLOGIA DA BRASIL ECODIESEL: PRINCIPAIS ATIVIDADES

\begin{tabular}{|c|c|}
\hline \multicolumn{2}{|r|}{2003} \\
\hline Julho & Constituição da subsidiária Buriti Agrícola Ltda. \\
\hline Novembro & $\begin{array}{l}\text { Início do primeiro núcleo de produção agrícola com base na } \\
\text { agricultura familiar. }\end{array}$ \\
\hline \multicolumn{2}{|r|}{2004} \\
\hline Abril & $\begin{array}{l}\text { Constituída a Ecotrans (subsidiária responsável pela } \\
\text { movimentação logística). }\end{array}$ \\
\hline \multicolumn{2}{|r|}{2005} \\
\hline Agosto & $\begin{array}{l}\text { Inauguração da primeira unidade industrial em Floriano, no } \\
\text { Piauí. }\end{array}$ \\
\hline Novembro & $\begin{array}{l}\text { Realização do primeiro leilão público para compra de } \\
\text { biodiesel no país, a Brasil Ecodiesel negociou } 38 \mathrm{mil} \mathrm{m}^{3} \text {. }\end{array}$ \\
\hline \multicolumn{2}{|r|}{2006} \\
\hline Março & $\begin{array}{l}\text { Realização do segundo leilão público para compra de } \\
\text { biodiesel no país, a Brasil Ecodiesel negociou } 21,78 \mathrm{mil} \mathrm{m}^{3} \text {. }\end{array}$ \\
\hline Maio & $\begin{array}{l}\text { Início das obras de construção da Planta Industrial de } \\
\text { Cratéus, no Ceará. }\end{array}$ \\
\hline Julho & $\begin{array}{l}\text { Início das obras de construção da Planta Industrial de } \\
\text { Iraquara, na Bahia. Realização do terceiro e quarto leilões } \\
\text { públicos para compra de biodiesel no país, a Brasil Ecodiesel } \\
\text { negociou } 428,22 \mathrm{mil} \mathrm{m}^{3} \text {. }\end{array}$ \\
\hline Outubro & Inauguração da Planta Industrial de Cratéus, no Ceará. \\
\hline Novembro & $\begin{array}{l}\text { Inauguração da Planta Industrial de Iraquara, na Bahia. } \\
\text { Abertura do capital na Bovespa. }\end{array}$ \\
\hline \multicolumn{2}{|r|}{2007} \\
\hline Fevereiro & $\begin{array}{l}\text { Realização do quinto leilão público para compra de biodiesel } \\
\text { no país, a Brasil Ecodiesel negociou } 8 \mathrm{mil} \mathrm{m}^{3} \text {. }\end{array}$ \\
\hline Maio & $\begin{array}{l}\text { Inauguração da Planta Industrial de Porto Nacional, no } \\
\text { Tocantins. }\end{array}$ \\
\hline Junho & $\begin{array}{l}\text { Inauguração da Planta Industrial de São Luis, no Maranhão e } \\
\text { de Rosário do Sul, no Rio Grande do Sul }\end{array}$ \\
\hline Novembro & $\begin{array}{l}\text { Realização do sexto e sétimo leilões públicos para compra de } \\
\text { biodiesel no país, a Brasil Ecodiesel negociou } 141 \mathrm{mil} \mathrm{m}^{3} \text {. }\end{array}$ \\
\hline
\end{tabular}

FONTE: Elaborado pelos autores com base em ANP, 2008 \& BRASIL ECODIESEL (2008b).

Em abril de 2008, as unidades processadoras de biodiesel da Brasil Ecodiesel tinham uma capacidade instalada para produzir pouco mais de $621 \mathrm{mil}^{3}$ anuais, o que representava $22 \%$ do total nacional. A produção acumulada de biodiesel entre 2005-2007 registrada pela ANP 
no país foi da ordem de 469 milhões de litros, deste total a Brasil Ecodiesel foi responsável por 246,9 mil m³ ou seja, 52,6\% da produção total (ANP, 2008).

Cabe destacar que a Brasil Ecodiesel foi a maior negociadora de biodiesel nos cinco primeiros leilões, nos quais se comprometeu a entregar até 31 de dezembro de 2007 cerca de 496 mil $\mathrm{m}^{3}$ de um total de $885 \mathrm{mil} \mathrm{m}^{3}$, ou seja, 56\%. Do volume negociado no sexto e sétimo leilões públicos (380 mil m³) com data de entrega até 30 de junho de 2008, as unidades industriais da Brasil Ecodiesel se comprometeram com $161 \mathrm{mil} \mathrm{m}^{3}$, por volta de 42,4\% do total (ANP, 2008).

Observa-se que em pouco tempo a empresa conseguiu instalar uma grande estrutura de processamento de biodiesel no país, bem como se tornou a maior produtora comercial. Cabe ressaltar que todas as unidades industriais da Brasil Ecodiesel são detentoras do Selo Combustível Social, ou seja, além de ter apresentado uma forte expansão de sua capacidade produtiva, também procurou promover a inserção da agricultura familiar (tabela 02).

A estrutura logística de produção e comercialização do biodiesel da Brasil Ecodiesel está organizada da seguinte maneira: i) coleta fragmentada da produção agrícola familiar; ii) centralização e escoamento desta produção para unidades de esmagamento e transporte do óleo vegetal para as unidades de processamento do biodiesel, quando essa não esteja integrada a unidade de processamento de biodiesel; iii) transporte para as unidades de processamento de outros insumos (álcool e catalisador); iv) transporte de subprodutos para comercialização ou para uso próprio (glicerina, torta etc.) e; v) distribuição do biodiesel (BRASIL ECODIESEL, 2007c).

TABELA 02 - UNIDADES PRODUTIVAS DA BRASIL ECODIESEL, CAPACIDADE ISNTALADA, AUTORIZADA, PREVISÃO DE AMPLIAÇÃO E DATA DE INAUGURAÇÃO

\begin{tabular}{|c|c|c|c|c|}
\hline $\begin{array}{l}\text { UNIDADES } \\
\text { PRODUTIVAS }\end{array}$ & $\begin{array}{l}\text { CAP. INST. } \\
\text { (MIL } \\
M^{3} / \text { ANO) }\end{array}$ & $\begin{array}{c}\text { CAP. AUT. PELA } \\
\text { ANP }(\text { MIL M M } / \text { ANO) }\end{array}$ & $\begin{array}{c}\text { PREVISÃO DE } \\
\text { AMPLIAÇÃO (MIL } \\
\text { M }^{3} / \text { ANO) }\end{array}$ & INAUGURAÇÃO \\
\hline Crateús & 118,8 & 108,0 & 165 & out $/ 06$ \\
\hline Floriano & 89,1 & 81,0 & & nov $/ 05$ \\
\hline Iraquara & 118,8 & 108,0 & 264,0 & nov/06 \\
\hline São Luis & 118,8 & 108,0 & 264,0 & jun/07 \\
\hline Porto Nacional & 118,8 & 108,0 & 264,0 & mai/07 \\
\hline Rosário do Sul & 118,8 & 108,0 & 264,0 & jun $/ 07$ \\
\hline TOTAL & 683,1 & 621,0 & $1.221,0$ & \\
\hline
\end{tabular}

FONTE: BRASIL ECODIESEL, 2007a \& ANP (2008).

Para isso, a empresa centralizou as atividades logísticas em sua subsidiária Ecotrans, que gerenciará os fretes das matérias-primas, do biodiesel e dos subprodutos, operando com frota própria, que será utilizada ainda para o fornecimento da assistência técnica aos agricultores. A 
Brasil Ecodiesel pretende aproveitar a Rede de Compras, com cadastro de 40 mil agricultores, 6 mil agentes agrícolas e 1,2 mil transportadoras (BRASIL ECODIESEL, 2007c).

No âmbito da assistência e capacitação técnicas, a empresa conta com 240 colaboradores distribuídos em 20 estados, voltados ao fomento das atividades vinculadas à agricultura familiar para a safra 2007/08. Diante das dificuldades de 2007, a empresa redefiniu seus objetivos quanto à mobilização de agricultores familiares. Esperava-se que cerca de 100 mil agricultores familiares participassem da produção de biodiesel, mas essa estimativa foi reduzida para cerca de 80 mil, os quais estão distribuídos em mais de 600 municípios (BRASIL ECODIESEL, 2007b).

A Brasil Ecodiesel possui ainda 210 escritórios com técnicos para auxiliar os produtores familiares em 436 municípios. Esses técnicos fazem quatro visitas a cada produtor durante todo o processo que vai do preparo do solo à colheita. A empresa também está investindo na formação de "agentes comunitários rurais", membros da sociedade local que se encarregarão com a intermediação entre o técnico e os agricultores.

A empresa também firmou diversos acordos com instituições públicas, privadas e representativas a fim de conseguir crédito para assistência e capacitação técnica dos produtores, fornecer sementes, garantir a comercialização dos produtos etc. Foram firmados acordos com a Confederação Nacional dos Trabalhadores Agrícolas (CONTAG), 12 federações estaduais de trabalhadores agrícolas, Banco do Estado do Rio Grande do Sul (BANRISUL), Banco Cooperativo Sicredi (SICREDI) (BRASIL ECODIESEL, 2007b \& ABRAMOVAY \& MAGALHÃES, 2007).

Em dezembro de 2007, a Brasil Ecodiesel já havia se consolidado como a maior empresa produtora de biodiesel do país, está presente em 19 Estados com seis fábricas de biodiesel, 3 unidades esmagadoras, 1 em construção e uma na fase de planejamento, 22 unidades de armazenamento de grãos e óleo, 3 laboratórios de certificação ${ }^{36}, 300$ mil hectares com parceiros agrícolas (57 mil parceiros), 63 mil hectares de terras próprias, sendo 20 mil hectares cultivados com pinhão manso, Capex (Capital Expenditure) de $\mathrm{R} \$ 180$ milhões e uma capacidade instalada de $621 \mathrm{mil} \mathrm{m}^{3}$ anuais (BRASIL ECODIESEL, 2008a).

\footnotetext{
36 A empresa possui Laboratórios de Certificação em Eusébio, no Ceará, em Porto Nacional, no Tocantins e em
} Rosário do Sul, no Rio Grande do Sul. Realiza experimentos em mais de 3 mil hectares com pinhão manso. 
A estratégia da Brasil Ecodiesel está estruturada num mix de óleos vegetais: óleo de soja (indústria processadora), girassol (agricultura familiar e empresarial), pinhão manso (agricultura familiar e terras próprias) e mamona (agricultura familiar). A diversificação das fontes pode mitigar os riscos e, ao mesmo tempo se beneficiar de potencial agrícola (BRASIL ECODIESEL, 2008a). Assim, está previsto que na temporada de plantio 2007/08 (set/2007 a jan/2008) ocorra o plantio de cerca de 12,1 mil hectares de pinhão manso em parte das fazendas localizadas nos Estados da Bahia, Ceará, Minas Gerais e Piauí (BRASIL ECODIESEL, 2007b).

O processo produtivo é caracterizado pela integração entre as fases de produção, isto é, a verticalização do processo. Essa estrutura contribui para garantir o suprimento de óleos vegetais e, também para mitigar as flutuações de preços de commodities e da taxa de câmbio (BRASIL ECODIESEL, 2008a).

Além da verticalização do processo, a empresa busca reduzir a parcela de óleo de soja utilizada no processamento do biodiesel. Segundo dados da firma de 2007 , cerca de $70 \%$ do óleo vegetal processado foram adquiridos no mercado de óleos vegetais (soja), 18\% do girassol e 12\% da mamona. A empresa projeta que em 2010, por volta de $20 \%$ sejam adquiridos no mercado de óleos vegetais (soja), 45\% de óleo de girassol, 30\% de mamona e 5\% extraído do pinhão manso. A origem dessas matérias-primas será: 20\% produzidas em terras da própria empresa; 25\% produzido pela agricultura empresarial; 35\% pela agricultura familiar e; o restante (20\%) adquirido no mercado (BRASIL ECODIESEL, 2008a).

Por fim, os desafios de médio e longo prazo postos à empresa são: incremento das cadeias agrícolas não alimentares (pinhão manso, mamona e girassol); elevação da eficiência industrial e com isso reduzir os custos, basicamente por meio da elevação da produtividade; manter relacionamentos de longo prazo no âmbito da comercialização e; buscar a redução do raio médio de transporte entre o plantio e processamento (BRASIL ECODIESEL, 2007a).

\section{CONCLUSÃO}

De acordo com a teoria do crescimento da firma desenvolvida por WOOD (1975), o objetivo das firmas não é só o lucro, mas também o ganho de parcelas do mercado. Analisandose a história da Brasil Ecodiesel, percebe-se a adoção desta estratégia, uma vez que a firma chegou a 53,1\% do mercado nacional em 2007. A conquista de parcelas sempre maiores de mercado é, 
claramente, uma das estratégias, que se materializa na capacidade instalada de produção, no volume de produção propriamente dito e, no volume negociado nos leilões realizados pela ANP.

No que se refere à estratégia, resgatamos a noção de CATERMOL (2006), quando afirma que as estratégias podem ser definidas como um conjunto de alternativas possíveis, incluindo os níveis de preço e de produção, as políticas de vendas e os projetos de investimento. A Brasil Ecodiesel utiliza a estratégias dos preços para poder participar e vencer parcelas dos leilões e poder entregar seus produtos no mercado; aumenta sua capacidade de produção através da construção de unidades industriais próprias, em muitos casos promovendo a integração das etapas de extração do óleo e de processamento do biodiesel (Tabela 02); com projetos de investimentos que lhe garantem presença em grande parte dos estados da nação (12 Estados).

PENROSE (2006) ao analisar o crescimento das grandes firmas destaca que elas tendem a ser não apenas diversificadas, mas extensamente integradas. A Brasil Ecodiesel busca diversificar sua atuação no sentido de garantir a manutenção de seu foco principal, que é a produção e venda de biodiesel. Neste sentido, pode-se destacar desde seus investimentos em fazendas próprias; como na instituição da Ecotrans, em 2004, empresa especializada em logística, inclusive com frota própria; sua estrutura de armazenamento; seus acordos com instituições públicas, privadas e representativas de agricultores; sua estrutura com Laboratórios de certificação entre outras. No que se refere à diversificação, destaque para os investimentos em soja, girassol, pinhão manso e mamona, como forma de não depender de uma única fonte de matéria-prima e de evitar as oscilações de preço e de mercado, bem como garantir o fornecimento de matériaprima para suas unidades processadoras.

SZMRECSÁNYI (2001 e 2007) ao estudar as obras de Penrose destaca enfaticamente a importância da pesquisa e dos laboratórios próprios na garantia de inovações de produto, de processo e na continuidade da empresa ao longo do tempo. A Brasil Ecodiesel teve todas as seis unidades produtivas instaladas no país projetadas e instaladas pela Tecbio (Tecnologias Bionergéticas Ltda), empresa criada em 2001, cujo objetivo principal era dar seqüência aos estudos sobre biocombustíveis. Essa estratégia lhe permite ter acesso à tecnologia, assim como facilita sua interação com a empresa fornecedora dos equipamentos e, portanto, the possibilita intervir ou promover alterações pontuais e específicas em sua estrutura industrial para aumentar a flexibilidade e rendimento dos equipamentos. 
Em resumo, o caso da Brasil Ecodiesel tem muito a contribuir para a análise do crescimento da firma num mercado relativamente novo, o de biodiesel. Como afirmado anteriormente, essa empresa dedica-se só à produção de biodiesel e nasce paralelamente ao marco regulatório brasileiro desse mercado. Mesmo assim, conseguiu imprimir uma dinâmica independente das demais empresas do setor e da própria dinâmica do programa federal de biodiesel. Para isso buscou construir uma estrutura diversificada de fornecimento de matériaprima (integrada e terceirizada), controle logístico, equipamentos relativamente flexíveis quanto à rota tecnológica e da fonte de matéria-prima bem como uma postura agressiva de comercialização.

\section{REFERÊNCIAS}

ABRAMOVAY, R. \& MAGALHÃES, R. (2007). O acesso dos agricultores familiares aos mercados de biodiesel: parcerias entre grandes empresas e movimentos sociais. Disponível em: <http://www.econ.fea.usp.br> Acesso em 20 fev. 2008.

ANP (2008). Diversas informações. Disponível em: <www.anp.gov.br> Diversos acessos.

BRASIL (2005a). Instrução Normativa $\mathbf{n}^{\mathbf{0}} \mathbf{1}$, de 05 de julho de 2005. Dispõe sobre os critérios e procedimentos relativos à concessão de uso do selo combustível social. Disponível em: <www.mda.gov.br> Acesso em 10 dez. 2006.

BRASIL (2005b). Instrução Normativa $\mathbf{n}^{\mathbf{0}}$ 2, de 30 de setembro de 2005. Dispõe sobre os critérios e procedimentos relativos ao enquadramento de projetos de produção de biodiesel ao selo combustível social. Disponível em: <http://www.mda.gov.br> Acesso em 10 dez. 2006.

BRASIL ECODIESEL (2007a). A maior empresa de biodiesel do Brasil. Disponível em: <http://www.ecolatina.com.br> Acesso em 20 fev. 2008.

BRASIL ECODIESEL (2008a). Biodiesel: uma experiência empresarial. Disponível em: <http://www.ccfb.com.br> Acesso em 20 fev. 2008.

BRASIL ECODIESEL (2008b). Histórico. Disponível em: < http://www.brasilecodiesel.com.br/quemsomos/historico> Acesso em 20 fev. 2008.

CARVAlHO, L. C., (2006), Salão Nacional dos Territórios Rurais: Política Nacional para o Biodiesel. Disponível em: <www.mda.gov.br> Acesso em 15 abr. 2007.

CATERMOL, F. Crescimento da firma e comércio exterior: revisitando a teoria de Adrian Wood. Revista de Economia Política. Vol. 26, n. 2 (102), p. 239-257, abril-junho/2006.

DALLA COSTA, A. Sucessão e sucesso nas empresas familiares. Curitiba: Juruá, 2006.

GARCIA, J. R.. O Programa Nacional de Produção e Uso de Biodiesel Brasileiro e a Agricultura Familiar na Região Nordeste. Campinas, 2007. 229 f. Dissertação (Mestrado em Desenvolvimento Econômico) - Instituto de Economia, Universidade Estadual de Campinas Unicamp. 
KAY, N. Hercules and Penrose, in Pitelis, 2002, p. 81-100.

KIM, L. Da imitação à inovação: a dinâmica do aprendizado tecnológico da Coréia. Campinas: Unicamp, 2005.

MAPA (2008a). Relação das Unidades Produtoras Cadastradas no Departamento da Canade-açúcar e Agroenergia. Disponível em: <www.agricultura.gov.br> Acesso em 20 fev. 2008.

MAPA (2008b). Dados estatísticos. Disponível em: <www.agricultura.gov.br> Acesso em 20 fev. 2008.

MDA (2006). Biodiesel e Inclusão Social (Apresentação em PPT). Disponível em: <http://www.biodiesel.gov.br/docs/02biodiesel_inclusao.ppt> Acesso em 20 nov. 2006.

MDA (2007). Empresas com selo combustível social vendem $\mathbf{9 9 \%}$ do biodiesel comercializado nos leilões. Disponível em: <www.mda.gov.br> Acesso em 20 nov. 2007.

MME (2004). Biodiesel: o novo combustível do Brasil (Programa Nacional de Produção e Uso do Biodiesel. Disponível em: <www.biodiesel.gov.br> Acesso em 20 jul. 2007.

NERY, L. (2008). Biodiesel. Disponível em: <www.sebraesp.com.br> Acesso em 20 fev. 2008.

PENROSE, E. Limits to the size and growth of firms. American Economic Review, XLV (2), mai 1955, p. 531-543 (Texto reproduzido em Pitelis, 2002, p. 30-42).

PENROSE, E. The growth of the firm, a case study of the Hercules Power Company. Business History Review, XXXIV (1), Spring, 1960, p. 1.23 (Texto reproduzido em Pitelis, 2002, p. 43-63).

PENROSE, E. The theory of the growth of the firm. Oxford: Basil Blackwell, 1959. Tradução para o português: SZMRECSÁNYI, T. Teoria do crescimento da firma. Campinas: Unicamp, 2006.

PITELIS, C. The growth of the firm: the legacy of Edith Penrose. Oxford: University Press, 2002.

SALOMÃO, A.; \& ONAGA, M. Etanol. O mundo quer, o Brasil tem. Revista Exame. São Paulo: Abril, ano 40, n. 12, ed. 870, p. 18-23, 21 de junho de 2006.

SZMRECSÁNYI, T. Contribuições de Edith Penrose às teorias do progresso técnico na concorrência oligopolista. Revista de Economia Política. Vol. 21, n. 1 (81), p. 167-172, janeiromarço 2001.

SZMRECSÁNYI, T. Contribuições de Edith Pernose (1914-1996) à historiografia das empresas multinacionais. Anais do VII Congresso Brasileiro de História Econômica e VIII Conferência Internacional de História de Empresas. Aracaju-SE, setembro de 2007.

TECBIO (2006). Tecbio - Tecnologias Energéticas Ltda.: apresentação da empresa. Disponível em: < http://www.tecbio.com.br/imagens/downloads/Biodiesel_tecbio.pdf> Acesso em 20 mai. 2007.

WOOD, A. A theory of profits. Cambridge: Cambridge University Press, 1975. Edição em português: Uma teoria de lucros. Rio de Janeiro: Paz e Terra, 1980. 